\title{
Airway Response to Electrical Field Stimulation in Sensitized Inbred Mice Passive Transfer of Increased Responsiveness with Peribronchial Lymph Nodes
}

\author{
Gary L. Larsen, Harald Renz, Joan E. Loader, Katherine L. Bradley, and Erwin W. Gelfand \\ Divisions of Basic Sciences and Pediatric Pulmonary Medicine, Department of Pediatrics, National Jewish Center for Immunology \\ and Respiratory Medicine, The Raymond and Beverly Sackler Foundation, Denver, Colorado 80206
}

\begin{abstract}
We have examined the effects of repeated exposure to antigen on airway responses to cholinergic stimulation in two inbred strains of mice that are similar in underlying cholinergic airway responsiveness, yet differ in their ability to produce IgE. Both BALB/c and SJL/J mice were repeatedly exposed to ovalbumin by inhalation for a 10-d period. While the BALB/c mice developed IgE antibody to this allergen, the SJL/J strain failed to mount an appreciable IgE response. In vitro assessments of the response of tracheal smooth muscle from saline exposed mice (controls) of both strains demonstrated responses to both methacholine and electrical field stimulation that were not significantly different between the strains. Following exposure to ovalbumin, the BALB/c strain developed a significant increase in their response to electrical field stimulation, while their response to methacholine was unaltered. In contrast, the in vitro responsiveness to these stimuli did not increase in $\mathbf{S J L} / \mathbf{J}$ mice following similar exposure to inhaled nebulized ovalbumin. The passive transfer of cells from the peribronchial lymph nodes of ovalbumin-sensitized BALB/c mice into syngeneic nonimmune mice also led to increases in responsiveness of tracheal smooth muscle to electrical field stimulation. In contrast, transfer of cells from nonsensitized mice did not alter responsiveness. These results suggest that murine species capable of developing an IgE response to allergen also develop alterations in the neural control of their airways. Further, this alteration appears to be lymphocyte dependent, in that cells found within peribronchial lymph nodes following allergen exposure are capable of transferring this increase in responsiveness to nonimmune mice. (J. Clin. Invest. 1992. 89:747-752.) Key words: airway responsiveness • BALB/c mice • immunoglobulin $\mathbf{E} \bullet$ lymphocytes $\bullet$ neural control of airways
\end{abstract}

\section{Introduction}

Study of allergen-induced increases in airway responsiveness has recently assumed new importance for several reasons. During the last decade, the hypothesis has evolved that asthma may almost always be associated with some type of IgE-related reaction, regardless of the age of the patient (1-3). In addition, allergen-induced increases in airway responsiveness are not

Address correspondence and reprint requests to Dr. Gary L. Larsen, Department of Pediatrics, National Jewish Center for Immunology and Respiratory Medicine, 1400 Jackson Street, Denver, CO 80206.

Received for publication 29 July 1991 and in revised form 08 November 1991.

J. Clin. Invest.

(c) The American Society for Clinical Investigation, Inc.

0021-9738/92/03/0747/06 \$2.00

Volume 89, March 1992, 747-752 transient, but can persist for days, weeks, or months $(4,5)$. Allergen exposure that leads to late phase reactions within the airways of atopic asthmatics may also contribute to the symptoms associated with viral upper respiratory infections (6), and to nocturnal exacerbations of asthma (7). Thus, much time and effort has been invested in developing mammalian models of allergen-induced changes in airway function that will allow more detailed study of this immunologic process and its consequences in terms of airway function (8). Unfortunately, most current models are limited in the questions that may be asked, in that the species employed are not well characterized from an immunologic standpoint. To circumvent this problem, investigations have been initiated in mice where there are many well characterized strains. The availability of mutants and inbred strains with immunologic deficiencies (9-11) also provides unique opportunities to study the role of single compartments of the immune system. While previous study in mice has been hampered because of limitations in assessing airway function, there have been recent inroads into such assessments, making use of this small mammal a more practical endeavor (12).

Because alterations of cellular and humoral immunity as they relate to control of airway responsiveness are poorly understood, we have developed a murine model that may help elucidate the pathogenesis of altered airway responsiveness. While IgE production can be induced in mice (13-19), especially after immunization that includes use of an adjuvant (18, 19), we have elected to sensitize mice through inhalation of allergen without use of adjuvants. This bypasses problems raised by the observations that adjuvants themselves may induce nonspecific $T$ cell and other inflammatory responses, as well as affect several cellular functions $(20,21)$. In addition, the inhaled route of antigen delivery represents a more relevant route of sensitization when the organ of study is the lung.

The purpose of this study was to determine if nebulization of ovalbumin (OVA) ${ }^{1}$ without the use of an adjuvant will induce an increase in airway responsiveness in airway smooth muscle from murine strains that either do or do not mount an appreciable IgE response to this antigen. Secondly, we sought to determine if altered responsiveness can be passively transferred from an immune to a nonimmune animal, utilizing lymphoid tissue obtained from the thoracic cavity of immune mice. Peribronchial lymph nodes (PBLN) were used for this purpose, as this lymphoid tissue has been found to significantly expand in size as a consequence of this immunization process (22). ${ }^{2}$ We found that this immunization procedure increased

1. Abbreviations used in this paper: EFS, electrical field stimulation; EU, ELISA units; MCh, methacholine; OVA, ovalbumin; PBLN, peribronchial lymph nodes; $T_{\max }$, maximal contractile response; TSM, tracheal smooth muscle segments.

2. Renz, H., H. R. Smith, J. E. Henson, B. S. Ray, C. G. Irvin, and E. W. Gelfand. Manuscript submitted for publication. 
airway responsiveness to electrical field stimulation only in the murine strain (BALB/c) that mounted an IgE response to OVA inhalation. Furthermore, an increase in responsiveness was produced through passive transfer of PBLN from OVA-immune to normal BALB/c mice.

\section{Methods}

Animals. Female BALB/c and SJL/J mice between 8 and 12 wk of age were obtained from the Jackson Laboratory (Bar Harbor, ME). The animals were virus free, as indicated by negative antibody titers to common murine viruses. The animals received an OVA-free diet. The Institutional Animal Care and Use Committee of the National Jewish Center for Immunology and Respiratory Medicine reviewed and approved all protocols employed in this study.

Immunization. Mice were immunized by ultrasonic nebulization of $1 \%$ OVA (chicken OVA, grade V; Sigma Chemical Co., St. Louis, MO) diluted in sterile PBS. The osmolarity of the OVA solution and PBS were 285 mosM. For this process, five mice were placed into a clear plastic box with a removable top (dimension $22 \times 23 \times 14 \mathrm{~cm}$ ). The OVA solution was aerosolized into one end of the box, using an ultrasonic nebulizer (PulmoSonic model 25; The DeVilbiss Co., Somerset, PA) and a continuous pressure of $5 \mathrm{psi}$. At the other end of the chamber were two small air holes $(0.5 \mathrm{~cm}$ in diameter) to ensure a continuous cross-current flow of air. As defined by laser nephelometry (23), more than $90 \%$ of the particles were in the $1-5-\mu \mathrm{m}$ range.

Immunization was carried out utilizing a daily 20 -min exposure to OVA over a 10-d period. Previous work with BALB/c mice had shown that this was the optimal immunization schedule for the selective production of allergen-specific IgE (22). ${ }^{2}$ Age-matched control animals were exposed to PBS alone, using the same protocol. $2 \mathrm{~d}$ after the protocol was completed, venous blood was obtained from the tail vein under anesthesia (Avidin, $5 \mathrm{mg} / \mathrm{g}$ i.p.). Blood was allowed to clot at room temperature, and serum was collected after centrifugation at $1,500 \mathrm{rpm}$ for $5 \mathrm{~min}$ at room temperature. Serum samples were stored at $-20^{\circ} \mathrm{C}$ until analyzed for anti-OVA IgE and IgG serum titers.

Determination of anti-OVA serum antibody levels. Anti-OVA IgE and IgG serum antibody levels were measured by ELISA in both strains of mice. Round-bottom microtiter plates (96-well Immunolon II; Dynatech Laboratories, Inc., Alexandria, VA) were coated with $20 \mu \mathrm{g} / \mathrm{ml}$ OVA diluted in $0.1 \mathrm{M} \mathrm{NaHCO}_{3}$ buffer, $\mathrm{pH}$ 8.2. After overnight incubation at $4^{\circ} \mathrm{C}$, plates were washed three times and blocked with $0.1 \mathrm{M}$ Tris-BSA ( $1 \%$, wt/vol) buffer, $\mathrm{pH} 9.6$, for $2 \mathrm{~h}$ at $37^{\circ} \mathrm{C}$. Serum samples were diluted in 0.1 M Tris-BSA-1\% Tween buffer starting at a 1:40 dilution. These and further $1: 2$ serial dilutions were added to the plates and incubated overnight at $4^{\circ} \mathrm{C}$. After washing, either alkaline phosphatase conjugated sheep-anti-mouse IgE (The Binding Site Inc., San Diego, CA) or goat anti-mouse IgG (Sigma Chemical Co.) diluted in Tris-BSA-1\% Tween buffer were added for an additional $2 \mathrm{~h}$. The reaction was developed with phosphatase substrate (Sigma Chemical Co.). Plates were read in a microplate autoreader (BioRad Laboratories, Pleasanton, CA) at $410 \mathrm{~nm}$.

The antibody levels of samples were calculated by comparison with internal standards. Anti-OVA IgE and IgG serum standards were obtained by intraperitoneal immunization of mice with OVA, according to previously published methods (13). Briefly, $10 \mathrm{~d}$ after a single injection of $10 \mu \mathrm{g}$ OVA diluted in PBS, the serum of five individual animals was collected. This standard serum was arbitrarily assigned a value of $1,000 \mathrm{U} / \mathrm{ml}$ anti-OVA IgE. To obtain IgG standard serum, five animals received two consecutive intraperitoneal injections of $50 \mu \mathrm{g}$ OVA per animal, with an interval of $3 \mathrm{wk}$ between the injections. Serum was collected at day 30 . The anti-OVA IgG titer was arbitrarily assigned a value of $1,000 \mathrm{U} / \mathrm{ml}$. In terms of both the IgE and IgG standard sera, the antibodies were still detectable when diluted 1:2,560, using the appropriate ELISA assay. Analysis of ELISA data was performed with the Microplate Manager software for the MacIntosh computer (BioRad Laboratories). The specificity of the ELISA was determined by prein- cubation of standard serum and serum samples from experimental animals with $100 \mu \mathrm{g} / \mathrm{ml}$ OVA. This procedure completely blocked activity in the ELISA, while preincubation with an irrelevant antigen (BSA, $100 \mu \mathrm{g} / \mathrm{ml}$; Sigma Chemical Co.) had no effect on the measurement of specific antibody titers.

Assessment of airway smooth muscle responsiveness. Airway smooth muscle responsiveness was assessed in vitro in two ways: $(a)$ through electrical field stimulation (EFS); and (b) by exposure to increasing concentrations of methacholine (MCh). $2 \mathrm{~d}$ after the last in vivo exposure to the aerosol of saline or antigen, mice were killed by cervical dislocation. Tracheal smooth muscle segments (TSM) that were $\sim 0.5 \mathrm{~cm}$ in length were cleaned of loose connective tissue. The tissue was placed in siliconized 20-ml organ baths (Harvard Apparatus Co. Inc., Millis, MA) and supported longitudinally by stainless steel wire triangular supports. Care was taken to place the membranous part of the TSM segment between the supports to maximize the recorded tension produced by isometric contractions. The lower support was attached to a glass hook at the base of the organ bath, and the upper support was attached via a gold chain to a FT.03 isometric force transducer (Grass Instrument Co., Quincy, MA). The latter was mounted on a rack and pinion clamp so that the resting length of the TSM segment could be adjusted. The tissues were bathed in a Krebs-Henseleit solution (mM): $118 \mathrm{NaCl}, 25 \mathrm{NaHCO}_{3}, 2.8 \mathrm{CaCl}_{2} \cdot 2 \mathrm{H}_{2} \mathrm{O}, 1.17 \mathrm{MgSO}_{4}$, $4.7 \mathrm{KCl}, 1.2 \mathrm{KH}_{2} \mathrm{PO}_{4}$, and $2 \mathrm{~g} /$ liter dextrose. The baths were aerated with a $95 \% \mathrm{O}_{2}-5 \% \mathrm{CO}_{2}$ gas mixture, and a pH of $7.43 \pm 0.03$ was established for the duration of each experiment. The temperature of the baths was maintained at $37^{\circ} \mathrm{C}$. Each TSM segment was equilibrated in the bath for $90 \mathrm{~min}$ at a tension of $1.5 \mathrm{~g}$. During this time, the tissue was challenged three times at $\sim 15$-min intervals, with a final concentration of $120 \mathrm{mM} \mathrm{KCl}$ in the bath. Tissues were rinsed with fresh buffer and allowed to relax to their initial tension after reaching maximal contraction. Recordings of resting tensions as well as all TSM contractile responses were made on a dynagraph recorder equipped with type 9853A couplers, $461 \mathrm{D}$ preamplifiers, and 412 amplifiers (model R612; SensorMedics Corp., Anaheim, CA). EFS was delivered by a Grass S44 stimulator connected to a stimulus isolation unit (SIU5; Grass Instrument Co.). The stimulus was applied transmurally across the tissues by means of parallel platinum electrodes (each $0.3 \mathrm{~cm}^{2}$ ). The optimal resting length for each tissue was established by assessing its maximal contractile response ( $T_{\max }$ ) to the following EFS: $8 \mathrm{~V}, 2$ ms pulse duration, $40 \mathrm{~Hz}$ stimulus frequency, and $82 \mathrm{~mA} / \mathrm{cm}^{2}$ current. Studies in rabbits and mice have shown no change in optimal resting length in the immune state (Larsen, G. L., J. Graves, and J. E. Loader, unpublished observations). After establishing optimal lengths, noncumulative stimulus-response curves were generated by varying the stimulus frequencies from 0.5 to $50 \mathrm{~Hz}$. Each EFS was maintained until a peak contractile response was obtained. Approximately, a 2-min recovery time elapsed between each successive stimulation. Studies within this laboratory have found that in murine airways, $40 \mathrm{~Hz}$ is the frequency at which the contractile responses were always maximal, and tissue damage due to EFS minimal. At higher current densities or voltages, the reproducibility of contractile responses diminished.

To further evaluate the characteristics of electrically-induced contractions in these murine species, the effects of the following agents (in final bath concentrations) were also examined in selected studies: $(a)$ atropine $\left(10^{-6} \mathrm{M}\right.$; Sigma Chemical Co.), a muscarinic cholinergic receptor antagonist; and $(b)$ tetrodotoxin $\left(4 \times 10^{-6} \mathrm{M}\right.$; Sigma Chemical Co.), an inhibitor of neural transmission.

To evaluate postsynaptic cholinergic sensitivity of tissues, cumulative dose-response curves to the cholinergic agonist methacholine $\left(10^{-8}\right.$ to $\left.10^{-4} \mathrm{M}\right)$ were separately obtained for each TSM segment. After obtaining a plateau response with each administered dose, the next addition of methacholine was added to the bath. Each dose was in half $\log$ increments.

At the end of each experiment, the TSM segments were blotted on a gauze pad and weighed. All tensions were expressed as either grams isometric tension per gram TSM weight $(\mathrm{g} / \mathrm{g})$, or as a percentage of the $T_{\max }$ to EFS or methacholine. The frequency that caused 25,50 , and 
$75 \%$ of the maximal contraction was calculated from linear plots of the contractile response versus the frequency of EFS, and expressed as the $\mathrm{ES}_{25}, \mathrm{ES}_{50}$, and $\mathrm{ES}_{75}$. Likewise, the concentration of methacholine that caused 25,50 , and $75 \%$ of the $T_{\max }$ was calculated from methacholine concentration-response curves, and expressed as the $\mathrm{EC}_{25}, \mathrm{EC}_{50}$, and $E_{75}$. All tissues were assessed in terms of their in vitro responsiveness by one investigator (J. E. Loader) who was blinded to the immunologic and treatment status of each airway.

Passive transfer of lymphocytes. For cell transfer experiments, mononuclear cells were prepared under sterile conditions from PBLN and spleens of immunized and nonimmunized BALB/c mice, respectively. Single-cell suspensions were prepared by dispersing small tissue pieces through stainless steel meshes. The dispersed cells were separated into mononuclear cells by density gradient centrifugation (Lymphocyte Preparation Media; Organon Teknika Corp., Durham, NC) for $15 \mathrm{~min}$ at $1,500 \mathrm{rpm}$ at room temperature. Cells from the interphase were washed three times in PBS. The cell concentration was adjusted so that the total volume of the transfer solution did not exceed $0.15 \mathrm{ml}$ per mouse. Desired cell numbers $\left(10^{7} \mathrm{PBLNs}\right.$, and $10^{7}-5 \times 10^{7}$ spleen cells) were transferred into syngeneic, naive, age- and sexmatched recipients by intravenous infusion into the tail vein. Immediately after the cell transfer, mice were exposed to a single OVA inhalation that was carried out as described above in the sensitization protocol. Further analysis of physiologic functions were performed $48 \mathrm{~h}$ after the cell transfer. This 48-h waiting period was chosen to parallel the time course of the experiments in which physiologic functions were performed $48 \mathrm{~h}$ after the last inhalation in the immunization protocol.

Data analysis. Immunoglobulin concentrations are expressed as the mean $\pm S D$ at each time point. The results of the in vitro assessments of airway responsiveness are reported as the mean $\pm \mathrm{SE}$ of the mean. Student's two-tailed unpaired $t$ test was used to determine the level of difference between animal groups.

\section{Results}

Antigen-specific IgE and IgG responses. Serum collected from both strains of mice before OVA exposure contained no OVAspecific IgE or IgG antibodies. The antibody profile measured 2 $\mathrm{d}$ after completion of the sensitization protocol was characterized by a significant increase of the anti-OVA IgE antibody titers in the BALB/c versus the $\mathrm{SJL} / \mathrm{J}$ strain. This data is displayed in Table $\mathrm{I}$, where the mean $\pm \mathrm{SD}$ of the antibody levels are expressed as ELISA units (EU) for five mice per group. The mice in any one group came from two independently performed experiments. While the IgE response was predominant in the BALB/c mice, the converse was found for the anti-OVA IgG titers; the BALB/c strain mounted a very small response compared to that seen in the SJL/J strain. In control mice of both strains that received inhalations of PBS solution alone for the same period of time, no OVA-specific IgE or IgG antibodies could be detected in serum samples collected $2 \mathrm{~d}$ after the last inhalation (data not shown).

Table I. Anti-OVA Antibody Levels after Immunization

\begin{tabular}{ccc}
\hline & \multicolumn{2}{c}{ Serum levels of anti-OVA* } \\
\cline { 2 - 3 } Strain & $\mathrm{IgE}$ & $\mathrm{IgG}$ \\
\hline & $E U / m l$ & $E U / \mathrm{ml}$ \\
$\mathrm{BALB} / \mathrm{c}$ & $315 \pm 85$ & $62 \pm 24$ \\
$\mathrm{SJL} / \mathrm{J}$ & $29 \pm 18$ & $1333 \pm 217$
\end{tabular}

* Mean \pm SD with five mice per group; expressed as ELISA units per milliliter of sera.
Table II. In Vitro Response of Tracheal Smooth Muscle to Methacholine

\begin{tabular}{lcrcc}
\hline \multicolumn{1}{c}{ Strain } & Treatment & $n$ & \multicolumn{1}{c}{$T_{\text {max }}{ }^{*}$} & EC $_{\text {so }}{ }^{*}$ \\
\hline BALB/c & PBS & 20 & $475 \pm 45$ & $6.2 \pm 0.5 \times 10^{-7}$ \\
SJL/J & PBS & 7 & $350 \pm 48$ & $7.8 \pm 1.7 \times 10^{-7}$ \\
BALB/c & OVA & 22 & $449 \pm 26$ & $7.0 \pm 0.7 \times 10^{-7}$ \\
SJL/J & OVA & 7 & $388 \pm 105$ & $18.0 \pm 5.7 \times 10^{-7}$ \\
& & & & \\
\hline
\end{tabular}

* Mean \pm SEM; expressed as grams tension/gram of tissue weight.

₹ Mean \pm SEM; expressed as molar concentration of methacholine causing $50 \%$ of the maximal contraction.

In vitro airway responsiveness to methacholine. The postsynaptic cholinergic sensitivity of airway smooth muscle of both murine strains was assessed after exposure to either PBS or OVA by assessing the in vitro characteristics of TSM to increasing concentrations of $\mathrm{MCh}$. These in vitro characteristics were expressed in terms of both the $T_{\max }$ and the $\mathrm{EC}_{25}$, $\mathrm{EC}_{50}$, and $\mathrm{EC}_{75}$. In the PBS-exposed BALB/c and SJL/J mice, there were no significant differences in the $T_{\max }$ or the concentration of drug needed to produce 25,50 , or $75 \%$ of the maximal response. In addition, exposure to OVA did not lead to significant alterations in these in vitro responses to this cholinergic agonist. The values of $T_{\max }$ and $\mathrm{EC}_{50}$ are shown for both BALB/c and SJL/J mice exposed to PBS or OVA in Table II.

In vitro airway responsiveness to electrical field stimulation. The response of TSM from BALB/c and SJL/J mice exposed to either PBS or OVA was also assessed to EFS. With the parameters used to stimulate the tissue, the responses were both neurally and cholinergically mediated, in that either tetrodotoxin (an inhibitor of neural transmission) or atropine (a muscarinic cholinergic receptor antagonist) completely abolished EFS-induced contractions in PBS (control) and OVA-exposed TSM from both strains of mice (data not shown). Control tissues from both strains were not significantly different in terms of their responses to $\mathrm{EFS}\left(T_{\max }\right.$ or $\mathrm{ES}_{25}, \mathrm{ES}_{50}$, and $\left.\mathrm{ES}_{75}\right)$. Thus, the $T_{\max }$ of SJL/J and BALB/c mice were $170 \pm 15 \mathrm{~g} / \mathrm{g}$ and $192 \pm 18$ $\mathrm{g} / \mathrm{g}$, respectively, while the $\mathrm{ES}_{25}, \mathrm{ES}_{50}$, and $\mathrm{ES}_{75}$ were $1.8 \pm 0.4$, $5.4 \pm 1.2$, and $14.6 \pm 4.1$ for the $\mathrm{SJL} / \mathrm{J}$ strain, and $1.9 \pm 0.3$, $4.2 \pm 0.3$, and $8.7 \pm 0.7$ for the BALB/c strain. In addition, exposure of the $\mathrm{SJL} / \mathrm{J}$ strain to OVA did not alter these parameters

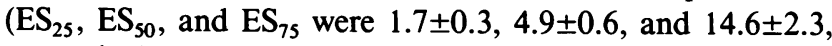
respectively.). On the other hand, exposure of the BALB/c mice to OVA was associated with a significant alteration in the response to EFS, without a significant change in $T_{\max }$. The responses to EFS are shown in Figs. 1 and 2, where it can be seen that immune as opposed to nonimmune (PBS exposed) $\mathrm{BALB} / \mathrm{c}$ mice responded with significantly greater contractile responses to EFS in the low and midfrequencies $(1,3$, and 5 $\mathrm{Hz}$ ) used to stimulate the tissue. This is demonstrated in terms of the full dose-response curves in Fig. 1, and in terms of the $\mathrm{ES}_{25}$ and $\mathrm{ES}_{50}$ values in Fig. 2. The levels of statistical significance are given in the figures. Significant differences were also found when the $\mathrm{ES}_{25}, \mathrm{ES}_{50}$, and $\mathrm{ES}_{75}$ values of OVA-exposed $\mathrm{BALB} / \mathrm{c}$ and $\mathrm{SJL} / \mathrm{J}$ mice were compared with $P$ values of $0.0008,0.0005$, and 0.0003 , respectively, for the three parts of the EFS-response curves.

Effect of passive transfer of lymphoid tissue on airway response to EFS. In order to assess the potential role of the lymphoid system in altering airway function, studies utilizing pas- 


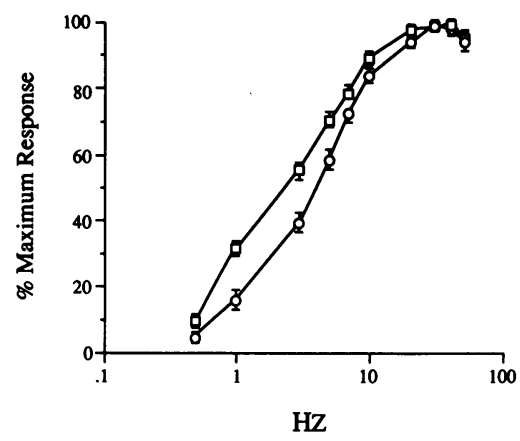

posed group showed significantly greater responses to electrical field stimulation when the stimulation frequencies were 1,3 , and $5 \mathrm{~Hz}(P=0.0001,0.0004$, and 0.004 , respectively).

sive transfer of lymphocytes were performed. Naive BALB/c mice were transfused with PBLN from OVA-treated mice that had mounted IgE responses to this allergen. For all the transfusions involving PBLN, $\sim 10^{7}$ cells were infused. To control for the effects of passive transfer of lymphoid tissue, from $10^{7}$ to 5 $\times 10^{7}$ spleen cells from normal BALB/c mice never exposed to OVA were infused into nonimmune syngeneic mice. Spleen cells were used, since PBLN from nonsensitized BALB/c mice were very small, and contained too few lymphocytes for transfer experiments. As shown in Fig. 3, passive transfer of PBLN from OVA-immune mice led to a significant increase in responsiveness $(P=0.04)$ that was comparable in magnitude to that seen in the OVA-immunized group. The increase in responsiveness in mice receiving PBLN could not be explained by the single exposure to OVA given after the transfer, in that mice that received splenic lymphocytes were also exposed to OVA, and failed to change responsiveness (Fig. 3). In addition, the $\mathrm{ES}_{50}$ of the normal mice receiving PBLN followed by OVA exposure $(3.1 \pm 0.2)$ was significantly less $(P=0.009)$ than the $\mathrm{ES}_{50}$ of mice that received normal splenic lymphocytes followed by OVA exposure $(4.0 \pm 0.1)$. While significant alterations were noted in the $\mathrm{ES}_{50}$ following the PBLN transfer, the in vitro response of TSM to MCh was not altered by passive transfer of either PBLN or spleen cells $\left(\mathrm{EC}_{50}\right.$ values $6.1 \pm 0.5$ $\times 10^{-7}$ and $5.6 \pm 0.4 \times 10^{-7}$, respectively).

\section{Discussion}

The potential importance of IgE-related reactions in terms of their ability to influence airway function has become apparent

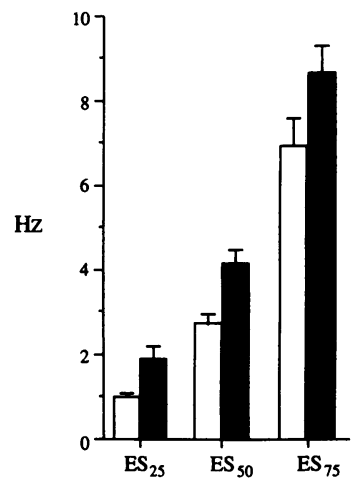

Figure 2. The in vitro response to electrical field stimulation (expressed as $\mathrm{ES}_{25}, \mathrm{ES}_{50}$, and $\mathrm{ES}_{75}$ ) for $\mathrm{BALB} / \mathrm{c}$ mice exposed for $10 \mathrm{~d}$ to either OVA (white open bars; $n=22$ ) or phosphate buffered saline (solid bars; $n=20$ ). The differences are significant for the first two comparisons $(P=0.001$ and 0.0004 , respectively), but not for the last $(P=0.063)$.

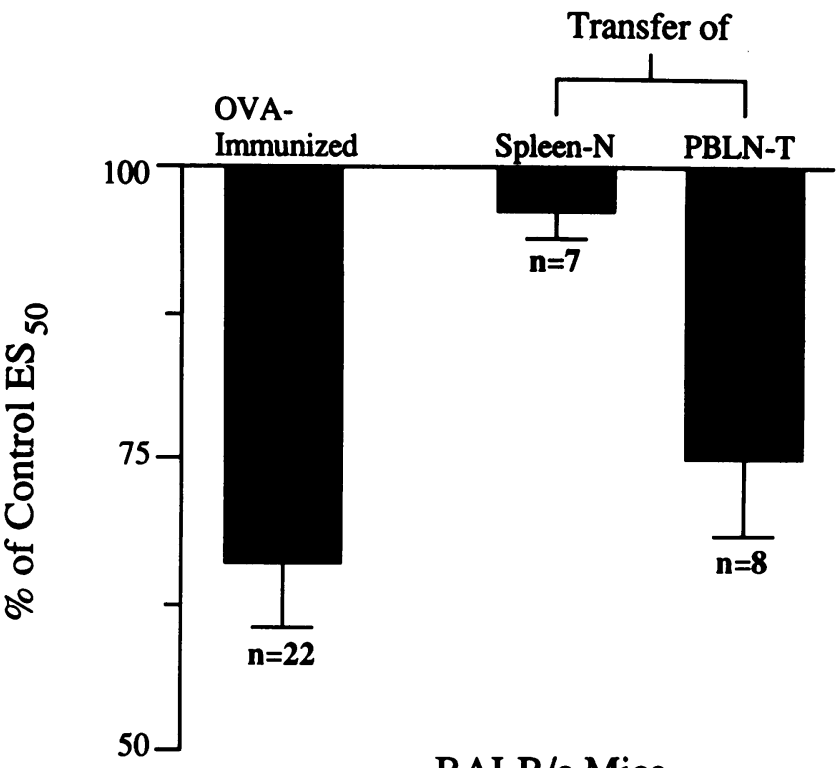

BALB/c Mice

Figure 3. The $\mathrm{ES}_{50}$ of three groups of $\mathrm{BALB} / \mathrm{c}$ mice expressed as a percentage of the $\mathrm{ES}_{50}$ found in PBS-exposed control mice of the same strain. The 22 OVA-immunized mice were significantly different from the PBS-exposed controls in terms of their ES $_{50}$ values $(2.7 \pm 0.2$ versus $4.2 \pm 0.3$, respectively). This is demonstrated in this figure by the $35 \%$ reduction in $\mathrm{ES}_{50}$ from the expected value (left bar). Passive transfer of spleen cells from normal mice (Spleen-N) into naive mice did not change the response to electrical field stimulation (middle bar). However, passive transfer of cells from peribronchial lymph nodes of OVA-treated mice (PBLN-T) led to a significant decrease in $\mathrm{ES}_{50}\left(\mathrm{ES}_{50}\right.$ of $\mathrm{PBLN}-\mathrm{T}$ group $=3.1 \pm 0.2 ; P=0.04$ versus $\mathrm{ES}_{50}$ of PBS-exposed controls; $P=0.009$ versus $\mathrm{ES}_{50}$ of Spleen-N group). The magnitude of change in $\mathrm{ES}_{50}$ for the group receiving PBLN-T is shown in the right bar.

from both clinical studies (1-7) and investigations employing animal models (8). For example, based upon epidemiologic observations, the hypothesis has been advanced that asthma may almost always be associated with some type of IgE-related reaction (3). While this and other clinical studies (reviewed in reference 5) have linked alterations in airway function to the presence of $\mathrm{IgE}$, investigations involving humans are limited in terms of the mechanistic questions that may be addressed. Thus, nonhuman mammalian models have been utilized to extend our knowledge of the biologic significance of these immunologic responses (8). For example, our laboratory previously reported that passively transferred rabbit sera containing allergen-specific IgE is capable of sensitizing naive rabbits so that they develop both early and late phase airway obstruction (24), as well as increased airway responsiveness after exposure to specific allergen $(25,26)$.

To extend these studies so that more basic questions may be addressed, murine models have been developed. These models have several advantages over previous models employed in our laboratory. In addition to being well characterized immunologically, it is clear that an IgE response to allergen may be elicited without use of an adjuvant, thus avoiding adjuvant-induced immunologic alterations $(13,20,21)$. We demonstrate that an IgE response is also easily produced via airway administration of allergen, producing local (pulmonary) immunologic changes that are likely to be more analogous to those found in humans 
with asthma. As shown in this study, changes in airway responsiveness associated with exposure to a potential allergen can be assessed in murine strains that are low or high IgE responders (13), thus providing a new and unique means to study the role of this antibody isotype in altering airway responsiveness. In addition, because cholinergic sensitivity of airways has been assessed in various strains of inbred mice (27), the strains employed for study can be matched for this characteristic, eliminating differences in baseline cholinergic responsiveness as a variable.

In this investigation, the IgE-responding BALB/c strain was contrasted with the poorly responsive $\mathrm{SJL} / \mathrm{J}$ strain by study of the effects of repeated OVA exposure on both immunologic responses and airway responsiveness. Analysis of serum antibody levels before and after a course of OVA exposure revealed appreciable increases in anti-OVA IgE in BALB/c, but not $\mathrm{SJL} / \mathrm{J}$ mice. The SJL/J mice clearly respond to inhalation of OVA, but predominately develop an IgG-antibody response. Anti-OVA IgG antibodies are known to appear later in the BALB/c strain (22), ${ }^{2}$ but are relatively deficient after only $10 \mathrm{~d}$ of OVA inhalation. This difference in IgE production allows comparison of the effects of repeated exposure to antigen on airway responsiveness when the immunologic responses in terms of isotypes produced are very different. In this study, alterations in airway responsiveness were only seen when mice produced allergen-specific IgE. When OVA-specific IgG was the predominant isotype, no alteration in airway function was observed. These results suggest that it takes more than repeated exposure to protein to alter airway function; immunologic events must transpire that lead to production of allergen-specific IgE.

In previous work utilizing this model in BALB/c mice, a 10-50-fold increase in the number of lymphocytes in PBLN of sensitized mice was noted $(22){ }^{2}$ As shown by flow cytometry using monoclonal antibodies against CD3 (T cells) and kappa light chain (B cells), this increase in lymphocytes was predominantly due to an increase in $\mathrm{T}$ cells. This observation raises the possibility that lymphocyte activation within the target organ (lung) may be important for the development of heightened airway responsiveness. The experiments involving passive transfer of mononuclear cells were undertaken to address this hypothesis. As outlined in the results, the increase in responsiveness was transferable with PBLN from IgE-sensitized BALB/c mice, but not with spleen cells from nonimmune mice. While this study does not address which cell(s) within PBLN were responsible for this transfer, it does lay the groundwork for further analysis of this response. Since $T$ cells are involved in the regulation of IgE production, this cell type may be very important in explaining the observed changes. Based on our findings and studies from other laboratories $(28,29)$, we speculate that activation and stimulation of $T$ cells is important in altering airway responsiveness.

$T$ cell activation is also important in the production of antigen-specific IgG. The fact that IgE production was associated with altered responsiveness while IgG production was not, suggests that specific subsets of $T$ cells need to be activated for this process to occur. While altered responsiveness was associated with the presence of anti-OVA IgE, it is unclear if IgE alone will alter responsiveness. Allergen challenge, or other products of this immunologic response (mediators, cytokines), may also be necessary to increase airway responsiveness. This continues to be the focus of ongoing work.
The responsiveness of airways in murine species may be evaluated in various ways. The response to agonists such as cholinergic agents or serotonin may be assessed by intravenous administration of the drugs $(27,30)$. While this method leads to measurable changes in lung function that reveal different responses between murine species $(27,30)$, as well as within a species after experimental manipulation (22), ${ }^{2}$ the results may not correlate with other methods of assessing airway responsiveness. For example, preliminary studies in canine airways have demonstrated that inhaled ozone will alter the airway response to inhaled agonist, while the intravenous response is unaltered (31). The in vivo response to an inhaled agonist may be assessed in mice. While this is the most widely used method of assessing airway responsiveness in man (32) and larger animal models (8), it has seen limited use in our murine studies due to the difficulty of delivering an aerosol to the airways while continually assessing airway function (33). The responsiveness of airway smooth muscle from mice may also be assessed in tissue baths (34). In addition, the in vitro response to endogenous release of acetylcholine produced by EFS may also be defined. Because of the relative simplicity and reproducibility of the latter two methods, as well as the insight they provide into airway control mechanisms when both are assessed (see next paragraph), these methods were employed in this study.

The pattern of response seen in the IgE-producing BALB/c mice was that of a significant increase in the in vitro responsiveness of the airways to electrical field stimulation, without an accompanying change in response to a cholinergic agent. We have noted a similar pattern in a rabbit model of allergen-induced late asthmatic responses (35). ${ }^{3}$ In addition, several mediators that may be generated during hypersensitivity reactions (substance $P$, platelet activating factor) produce similar patterns of altered responsiveness in airway smooth muscle (3639). In general, this has been interpreted to represent an alteration in neural control of airways. While the hypothesis has been advanced that the pattern is most consistent with enhanced release of acetylcholine from neural terminals (35-39), a proper assessment of this hypothesis awaits the development of more sensitive techniques to assess acetylcholine release within airways. In studies involving airway smooth muscle from humans, most in vitro assessments of airway responsiveness to cholinergic agents have failed to find differences between airways from normal subjects and subjects with asthma (reviewed in 40). On the other hand, one recent report did suggest that airways from people with fatal asthma may be more responsive to electrical field stimulation than airways from subjects without asthma (41).

The reduction in $\mathrm{ES}_{50}$ found in this study is comparable to that reported in other studies. Within our laboratory, allergen exposure in immune rabbits produced $\sim$ a $35 \%$ reduction in $\mathrm{ES}_{50}(35),{ }^{3}$ while the in vivo responsiveness to inhaled histamine increased $\sim 6.5$-fold in the same model (25). Other investigators (36-39) have reported significant reductions in mean values of $\mathrm{ES}_{50}$ that varied from $30 \%$ (36) to $50 \%$ (39) below baseline values. Thus, the percent decreases in $\mathrm{ES}_{50}$ shown in Fig. 3 are comparable to those reported by other investigators. As suggested by the small variances, the results are highly reproducible. The use of inbred strains of mice where genetically determined characteristics are minimized

3. Ando, R. E., C. G. Irvin, G. L. Larsen, and D. T. Tanaka. Manuscript submitted for publication. 
may help explain the small variances. From a statistical standpoint, the differences noted between groups are very significant.

In summary, this study provides evidence for development of increased airway responsiveness to EFS in IgE-responding BALB/c mice after sensitization with OVA in the absence of adjuvant. Alterations in responsiveness were not seen in mice exposed to OVA who failed to mount an IgE response. The pattern of altered in vitro responsiveness suggests the immunologic response leading to IgE sensitization alters neural control of airways. The ability to passively transfer this response with mononuclear cells from PBLN of immune mice suggests an important role for pulmonary lymphocytes in the pathogenesis of this airway dysfunction. Further development of this model should allow better definition of the immunologic mechanisms responsible for this alteration in airway function.

\section{Acknowledgments}

This work was supported in part by National Institutes of Health grants AI-26490, AI-29704, and P01 HL-36577. Dr. Harald Renz is supported by a grant from the Deutsche Forschungsgemeinschaft $(\operatorname{Re} 737 /$ 1-1). Dr. Erwin Gelfand is a Scholar of the Raymond and Beverly Sackler Foundation.

\section{References}

1. Kulczycki, A., Jr. 1981. Role of immunoglobulin E and immunoglobulin E receptors in bronchial asthma. J. Allergy Clin. Immunol. 68:5-14.

2. Platts-Mills, T. A. E., and M. D. Chapman. 1987. Dust mites: immunology, allergic disease, and environmental control. J. Allergy Clin. Immunol. 80:755775.

3. Burrows, B., F. D. Martinez, M. Halonen, R. A. Barbee, and M. G. Cline. 1989. Association of asthma with serum IgE levels and skin-test reactivity to allergens. N. Eng. J. Med. 320:271-277.

4. Cartier, A., N. C. Thomson, P. A. Frith, R. Roberts, and F. E. Hargreave. 1982. Allergen-induced increase in bronchial responsiveness to histamine: relationship to the late asthmatic response and change in airway caliber. J. Allergy Clin. Immunol. 70:170-177.

5. O'Byrne, P. M., J. Dolovich, and F. E. Hargreave. 1987. State of art. Late asthmatic responses. Am. Rev. Respir. Dis. 136:740-751.

6. Lemanske, R. F. Jr., E. C. Dick, C. A. Swenson, R. F. Vrtis, and W. W. Busse. 1989. Rhinovirus upper respiratory infection increases airway hyperreactivity and late asthmatic reactions. J. Clin. Invest. 83:1-10.

7. Mohiuddin, A. A., and R. J. Martin. 1990. Circadian basis of the late asthmatic response. Am. Rev. Respir. Dis. 142:1153-1157.

8. Larsen, G. L. 1991. Experimental models of reversible airway obstruction. In The Lung: Scientific Foundations. R. G. Crystal, J. B. West, P. J. Barnes, N. S. Cherniack, and E. R. Weibel, editors. Raven Press, Ltd., New York. 953-965.

9. Ito, K., T. Ogita, M. Suko, M. Mori, K. Kudo, T. Hayakawa, H. Okudaira, and Y. Horiuchi. 1979. IgE levels in nude mice. Int. Arch. Allergy Appl. Immunol. 58:474-476.

10. Jacoby, W., P. V. Cammarata, S. Findlay, and S. H. Pincus. 1984. Anaphylaxis in mast cell-deficient mice. J. Invest. Dermatol. 83:302-304.

11. Savelkoul, H. F. J., T. W. van den Akker, P. W. C. Soeting, A. van Oudenaren, and R. Benner. 1989. Modulation of total IgE levels in serum of normal and athymic nude BALB/c mice by $T$ cells and exogenous antigenic stimulation. Int. Arch. Allergy Appl. Immunol. 89:113-119.

12. Martin, T. R., N. P. Gerard, S. J. Galli, and J. M. Drazen. 1988. Pulmonary responses to bronchoconstrictor agonists in the mouse. J. Appl. Physiol. 64:2318-2323.

13. Holt, P. G., A. H. Rose, J. E. Batty, and K. J. Turner. 1981. Induction of adjuvant-independent IgE responses in inbred mice: primary, secondary, and persistent IgE responses to ovalbumin and ovomucoid. Int. Arch. Allergy Appl. Immunol. 65:42-50.

14. Taylor, W. A., D. Sheldon, and D. H. Francis. 1980. IgE antibody formation in BALB/c mice without adjuvant: induction of responses to grass pollen extract and to a hapten-carrier conjugate. Immunology. 39:583-588.

15. Levine, B. B., and N. M. Vaz. 1970. Effect of combinations of inbred strain, antigen and antigen dose on immune responsiveness and reagin production in the mouse. A potential mouse model for immune aspects of human atopic allergy. Int. Arch. Allergy Appl. Immunol. 39:156-171.

16. Hall, E., S. Ahlstedt, and A. Kristofferson. 1982. Boosterable IgE antibody response in mice without the use of adjuvant. Int. Arch. Allergy Appl. Immunol. 67:96-98.

17. Ahlstedt, S., and B. Björkstén. 1983. Specific antibody responses in rats and mice after daily immunization without adjuvant. Int. Arch. Allergy Appl. Immunol. 71:293-299.

18. Vaz, E. M., N. M. Vaz, and B. B. Levine. 1971. Persistent formation of reagins in mice injected with low doses of ovalbumin. Immunology. 21:11-15.

19. Beck, L., and H. L. Spiegelberg. 1989. The polyclonal and antigen-specific IgE and IgG subclass response of mice injected with ovalbumin in alum or complete Freund's adjuvant. Cell. Immunol. 123:1-8.

20. Bomford, R. 1980. The comparative selectivity of adjuvants for humoral and cell-mediated immunity. I. Effect on the antibody response to bovine serum albumin and sheep red blood cells of Freund's incomplete and complete adjuvants, alhydrogel, Corynebacterium parvum, Bordetella pertussis, muramyl dipeptide and saponin. Clin. Exp. Immunol. 39:426-434.

21. Bomford, R. 1980. The comparative selectivity of adjuvants for humoral and cell mediated immunity. II. Effect on delayed-type hypersensitivity in the mouse and guinea pig, and cell-mediated immunity to tumour antigens in the mouse of Freund's incomplete and complete adjuvants, alhydrogel, Corynebacterium parvum, Bordetella pertussis, muramyl dipeptide and saponin. Clin. Exp. Immunol. 39:435-441.

22. Renz, H., H. Smith, C. Irvin, G. Larsen, and E. W. Gelfand. 1991. Development of in vivo and in vitro bronchial hyperresponsiveness in a murine model is associated with IgE production but not with acute inflammation. J. Allergy Clin. Immunol. 87:168. (Abstr.)

23. Clay, M. M., D. Pavia, S. P. Newman, and S. W. Clarke. 1983. Factors influencing the size distribution of aerosols from jet nebulization. Thorax. 38:755-759.

24. Behrens, B. L., R. A. F. Clark, W. Marsh, and G. L. Larsen. 1984. Modulation of the late asthmatic response by antigen-specific immunoglobulin $\mathbf{G}$ in an animal model. Am. Rev. Respir. Dis. 130:1134-1139.

25. Marsh, W. R., C. G. Irvin, K. R. Murphy, B. L. Behrens, and G. L. Larsen. 1985. Increases in airway reactivity to histamine and inflammatory cells in bronchoalveolar lavage after the late asthmatic response in an animal model. Am. Rev. Respir. Dis. 131:875-879.

26. Murphy, K. R., M. C. Wilson, C. G. Irvin, L. S. Glezen, W. R. Marsh, C. Haslett, P. M. Henson, and G. L. Larsen. 1986. The requirement for polymorphonuclear leukocytes in the late asthmatic response and heightened airways reactivity in an animal model. Am. Rev. Respir. Dis. 134:62-68.

27. Levitt, R. C., and W. Mitzner. 1988. Expression of airway hyperreactivity to acetylcholine as a simple autosomal recessive trait in mice. FASEB J. (Fed. Am. Soc. Exp. Biol.) 2:2605-2608.

28. Sustiel, A., and R. Rocklin. 1989. T cell responses in allergic rhinitis, asthma and atopic dermatitis. Clin. Exp. Allergy. 19:11-18.

29. Corrigan, C. J., and A. B. Kay. 1990. CD4 T-lymphocyte activation in acute severe asthma. Relationship to disease severity and atopic status. Am. Rev. Respir. Dis. 141:970-977.

30. Levitt, R. C., and W. Mitzner. 1989. Autosomal recessive inheritance of airway hyperreactivity to 5-hydroxytryptamine. J. Appl. Physiol. 67:1125-1132.

31. Bethel, R. A., and C. L. McClure. 1990. Differential effect of ozone on the response of canine airways to nebulized and parenteral acetylcholine. Am. Rev. Respir. Dis. 141:A658. (Abstr.)

32. Durham, S. R., C. F. Craddock, W. O. Cookson, and M. K. Benson. 1988. Increases in airway responsiveness to histamine precede allergen-induced late asthmatic responses. J. Allergy Clin. Immunol. 82:764-770.

33. Smith, H. R., B. S. Ray, and C. G. Irvin. 1991. A murine model for the late phase pulmonary response, airways hyperresponsiveness and airways inflammation following antigen inhalation. Am. Rev. Respir. Dis. 143:A433. (Abstr.)

34. Weinmann, G. G., C. M. Black, R. C. Levitt, and C. A. Hirshman. 1990 In vitro tracheal responses from mice chosen for in vivo lung cholinergic sensitivity. J. Appl. Physiol. 69:274-280.

35. Ando, R. E., D. T. Tanaka, C. G. Irvin, and G. L. Larsen. 1987. Neurally mediated contraction of airway smooth muscle from immune rabbits challenged with antigen or saline aerosol. Am. Rev. Respir. Dis. 135(2):A271. (Abstr.)

36. Tanaka, D. T., and M. M. Grunstein. 1986. Effect of substance P on neurally mediated contraction of rabbit airway smooth muscle. J. Appl. Physiol. 60:458-463.

37. Sekizawa, K., P. D. Graf, and J. A. Nadel. 1989. Somatostatin potentiates cholinergic neurotransmission in ferret trachea. J. Appl. Physiol. 67:2397-2400.

38. Bethel, R. A., S. P. Curtis, D. C. Lien, C. G. Irvin, G. S. Worthen, A. R. Leff, and P. M. Henson. 1989. Effect of PAF on parasympathetic contraction of canine airways. J. Appl. Physiol. 66:2629-2634.

39. Tamaoki, J., N. Sakai, K. Kobayashi, T. Kanemura, T. Shibasaki, and T. Takizawa. 1989. Corticotropin-releasing factor potentiates the contractile response of rabbit airways smooth muscle to electrical field stimulation but not to acetylcholine. Am. Rev. Respir. Dis. 140:1331-1335.

40. Black, J. L., and C. L. Armour. 1989. Induction of hyperresponsiveness in human airways in vivo and in vitro. Pulm. Pharmacol. 2:169-178.

41. Bai, T. R. 1990. Abnormalities in airway smooth muscle in fatal asthma. Am. Rev. Respir. Dis. 141:552-557. 